\title{
浅谈高等院校 “智慧党建”
}

\author{
赵研 赵楠 许磊
}

北京经济管理职业学院

DOI:10.32629/er.v2i12.2303

[摘 要] 高等院校的党建工作是高等院校实现育人目标的重要保障。随着现代信息技术的不断推进与发展,党建工作也面临着新的要求, “智 慧党建” 是高等院校党建工作的重要改革方向。“智慧党建” 是基于互联网技术形成的党建工作平台,能够推动党建工作与学生群体的联系。“智 慧党建” 的工作模式丰富了高等院校党建工作的形式,提高了高等院校党建工作的效率,并且以更加便捷的方式增加党组织内部的沟通与交流。 [关键词] 高等院校; 互联网; 党建; “智慧党建”

“智慧党建” 是互联网+党建的新模式, 是运用信息化技术, 整合各方 资源, 更有效的加强组织管理, 提高服务群众水平, 扩大党在网络世界的存 在感和数字化影响力, 提高党的执政能力, 巩固党的执政基础的新平台、新 模式、新形态。

高等院校的 “智慧党建” 主要是指高等院校的党建工作中通过借助现 代的互联网、物联网信息技术手段, 对党建活动的各种需求进行智能响应, 形成一个具备实时的信息收集、处理, 互联互通以及智能分析的党建工作 模式。对党建资源的全面公开, 对党建活动的信息内容进行全面的优化, 不仅能够对高等院校的党组织、党员思想活动进行实时的感知, 而且能够 让高等院校党组织与其他院校党组织实现信息的互联互享。

\section{1 高等院校 “智慧党建” 工作的优势}

1. 1 智慧党建平台能够为高等院校党建工作提供多样化服务

目前我国的高等院校的大学生为 98 后的大学生群体, 这部分群体成长 于互联网的信息时代, 对于互联网的敏感度较高, 追求新鲜、时尚、有趣事 物的兴趣度较高, 针对群体的特点, 高等院校的党建工作方法应当进行创 新, 利用计算机网络技术, 通过学生易于接受的方式进行党建工作, 从而有 效提升党建工作的效率。譬如, 从互联网渠道搜索党建工作的相关内容, 让大学生自己制作关于党建工作建设的短视频, 发布在快手APP、抖音APP 平台上, 通过观看优秀的视频的方式, 宣传与弘扬社会主义思想文化。

高等院校的 “智慧党建” 平台的出现, 极大的丰富高等院校党建工 作的形式。传统的高等院校的党建工作主要是依据报告、下发文件资料、 向学生宣读文件、对学生进行党政机关报纸内容的宣读方式, 这种单向 性的师生党员思想灌输的方式主要是实现自我的教育, 效果有限。“智慧 党建”平台的出现丰富党建工作宣传的形式, 丰富了党建工作的内容, 突 破了时空的限制, 使得高等院校的党建工作不在局限于传统的形式, 采 用 “一对多” 的信息发散形式, 能够以一种更加高效, 并且互动性更强的 方式进行党建活动, 有助于实时的了解党组织的活动、党员干部的思想 动态。

\section{2 智慧党建平台为高等院校党建工作汇集了舆情信息}

“智慧党建” 平台的构建能够有效的对当前的舆情信息进行搜集, 反 映高等院校大学生群体的思想动态。在 “智慧党建” 平台上可以通过数据 化的信息汇总分类, 反映出高等院校大学生群体的诉求。“智慧党建” 平台 的搭建会对党的动员方式、党的思想传播方式产生重大的变革, 不仅突破 了高等院校党组织依靠自上而下的信息传播、层层动员的传统模式, 而且 能够有效的对党员的思想意识动态进行掌握, 提供一个互动性、实时性的 平台, 及时有效的汇集信息。由于高等院校的党员数量多, 不同的年龄及地 域都会产生不同的舆情反应。因此, 要加强高等院校的党内舆情信息的汇 集, 必须要将个体的党员信息进行全面汇集。运用 “智慧党建” 平台, 利用
现代的信息化技术对党内的與情信息进行汇总, 使得党内的與情信息汇总 更加具有针对性, 有助于党建工作的开展。

\section{3 “智慧党建” 平台顺应大学生的习惯与需求}

从高等院校的党建工作方式上看, 主要是依靠高等院校的党组织下发 一些党报或者是上党课的方式传达党的思想, 这种传统的形式不仅信息容 量比较有限, 传播速度较慢, 且不符合党员学生的实际需求, 对党员学生产 生的实际影响有限。运用 “智慧党建” 平台, 能够简化繁琐的操作流程, 将一些微信、QQ、微博等符合高等院校大学生使用习惯的社交方式与党建 工作进行连接, 提高效率。自媒体的兴起也使大学生群体通过互联网的渠 道参与党员生活的主动性变高。

互联网信息化的发展使得高等院校的信息传播更加快捷, 且网络环境 中话语权的开放性使得大学生思想意识形态更加具有开放性, 思想意识变 得更加的复杂化, 各种政治力量形态对大学生党员的思想观念产生冲击, 对党员学生的管理提出新的挑战与要求。“智慧党建” 平台的出现创新了 学生党员参与党建活动的方式, 迎合了高等院校党员学生的习惯, 通过互 联网信息化的方式将学生党员的舆情进行搜集, 可以及时进行回应, 有效 推动了党建工作的效率。

\section{2 高等院校 “智慧党建” 平台建设主要模式}

2. 1 微信公众平台智慧党建模式

微信作为社交软件深受高等院校大学生群体的喜爱, 微信公众平台不 仅能够实现用户的多向沟通, 而且发送的内容不再局限于短信, 还可以通 过图片、视频、语音方式进行信息的传播。微信公众平台的 “智慧党建” 模式, 通过学生党员关注微信公众号, 及时发布党建信息并了解学生党员 的动态。例如, 兰州交通大学环境与市政工程学院在2016年开设学院的党 建微信公众号, 通过搭建微信公众号的方式, 运用互联网传播组织纪律, 并 且将社会主义的核心价值观、大学生的思想政治教育内容发布到网络中, 通过运用网络宣传的方式, 强化党员教育。兰州交通大学环境与市政工程 学院的党建微信公众号上通过将党员服务、党员管理、党员活动作为主要 的板块, 通过微信公众号的方式让学生党员参与到党建活动中, 从入党指 南、手指党校、时事热点、党员服务四个方面向学生党员传递国家政策方 针, 有效的增强学生党员的党性修养, 带动学生党员占领互联网文化阵地。

\section{2 “三微一网” 智慧党建模式}

网络信息化的发展使得高等院校的大学生对互联网信息的接触较多, 而且新媒体的出现与发展使得高等院校的大学生党员的思想形态发生一 定的变化, 其不仅改变高等院校学生党员的生活, 也给其思想带来一定的 影响。十八大以来提出建设学习型的高等院校, 在高等院校的党建工作中 也需要不断的进行创新, 目前 “三微一网” 的智慧党建模式受到广泛的推 崇。以 “微博、微信、微课堂” 以及党建官网作为载体的智慧党建模式, 


\section{网络环境下高职院校创新教育管理论}

朱娅

重庆电子工程职业学院

DOI:10.32629/er.v2i12.2258

[摘 要] 随着信息技术的发展以及互联网与人类社会的深入融合,职业教育管理的重点已转向学生的教育管理。这是一项必须高度负责和以任 务为导向的工作, 这不仅给工作带来了很高的回报。高职院校的学生管理带来了新的挑战和机遇。为此, 针对不同层次的学生有不同的教育管理 方法,因此职业院校也有自己的教育理念和教育方法。一般在初中或高中毕业后就可以入学的学生。他们有自己的个性特征和行为习惯。在教 育管理中,必须采取一些相应的方法来教育学生。

[关键词]网络环境; 职业院校; 创新教育

\section{1 网络环境下高职院校学生教育管理的机遇与挑战}

1. 1 网络环境对高职院校学生的负面影响

网络信息技术没有绝对的东西。从客观的角度来看, 网络技术可以说 是一把双刃刀。不良的网络信息将对学生的实际健康成长产生不同程度的 影响, 并且还将传播到高职院校的学生管理中工作。从主观角度分析其影 响, 我们可以将其概括为以下几个方面:

首先, 开放的网络环境将展现出不同水平的民族文化, 思想, 行为等, 这也会对学生的实际价值观产生一定的影响。尽管大学生已经具有一定 的辨别能力, 但在一些根深蒂固的文化和思想中仍然存在一些判断错误, 这也将导致一些学生偏离正确的思想轨道, 并对日常管理工作产生一定 的影响。

其次, 虚拟网络环境将为高职院校的学生提供 “隐形” 的外衣。在这 种环境下, 学生会感到不舒服, 这会使学生放宽要求。从长远来看, 它也很 容易受到互联网上负面文化的影响, 甚至影响自身和学校的发展。

最后, 网络环境中有许多娱乐项目, 许多学生将沉浸其中。这种问题会 影响到高职院校的管理。

1.2网络环境对高职院校学生的积极影响

在良好的网络环境和正确的信息手段的指导下, 将大大促进高职院校 学生管理工作。它产生的作用可以从以下几个方面进行解释:

首先, 通过使用网络技术, 学生可以有效地改善动态信息的接收。高职 院校管理人员可以分析学生在网络上的不同动态, 可以有效地分析学生的 心理观和心理状况。同时, 结果可以用来更好地指导学生的发展。

其次, 网络技术可以有效拉近学生与老师, 学生与学校之间的距离。例 如, 网络通信的迅速发展使师生之间的交流更加多样化。微信和QQ等社交 软件的使用使师生之间的交流更加紧密。同时, 高职院校管理人员可以通 过这些软件快速获取学生的反馈信息, 实现信息传递的 “破坏性”, 在一定 程度上促进了学校与学生之间的距离。

不仅能让大学生党员学习最新的时事政策, 而且能够增强互动性。如安徽 经济管理学院通过打造 “三微一网” 的智慧党建模式, 通过建立新媒体的 联盟模式, 打造党建的网络栏目, 在党建平台上策划党建活动的精品内容, 并且组织一系列的党建网络 “微” 活动。通过 “三微一网” 的智慧党建平 台的构建, 有效的强化高等院校学生党员的與情引导, 而且成立学生党员 的與情信息中心, 建立有效的网络信息监管与與情处理应对的机制, 针对 大学生党员的與情信息进数据信息的收集与反馈。并且通过 “三微一网” 的智慧党建平台, 通过网络渠道宣传思想政治教育, 弘扬校园网络文化。

互联网+ “智慧党建” 模式, 是高校党建工作革新的必然选择。随着互
最后, 通过网络技术的应用, 有效拓宽了高职院校学生管理的渠道。高 职院校的学生管理人员可以结合网络设计针对性的学生管理系统。该系统 包括对学生的评估, 文件管理, 考试详细信息等, 不仅提高了高职院校学生 管理的效率, 而且减少了不必要的人力资源浪费。

\section{2 网络环境下高职院校学生教育管理策略分析}

2.1给学生留下好印象

在我们学校新生汇报之后, 我们必须首先进行为期一周的军事训练。 在白天的军事训练中, 老师必须与讲师合作, 以使学生不迟到, 不早, 不正 确, 不认真。在晚上的自学中, 老师应向学生讲解学院和系的规章制度, 让 学生了解学校, 知道该做什么和不该做什么。例如, 我通常告诉学生何时给 他们上第一堂课。不管您以前的文化研究结果如何, 既然您来到一所新学 校, 您的出发点是相同的, 老师将是公平的。善待每个学生。这使学生知道 您是一个严谨的人, 一个可以信任他们的人, 从而给学生留下良好的第一 印象。

2. 2 培养学生团队意识

人们经常说: “筷子一眼就会折断; 一根筷子是不变的。”班上的学生 也是如此。如果他们不团结, 将会给教师的管理带来很大的困难。相反, 如果班上的学生团结一致, 那么他们将是一门优秀的班。实际上, 每个学生 都有自己的长处。关键是看老师是否可以挖出来。我经常告诉学生这样的 故事。“唐Yan带了三个学徒向西方学习。然后四个男人和女人组成了一个 团队。他们在团队中不可或缺。每个人都有自己的角色。” 故事结束后, 以下学生将开始谈论它。有人说唐Yan没用, 有人说没用过猪, 等等。这时, 我告诉学生, 他们实际上在这支队伍中扮演着不可替代的角色。唐Yan有一 个坚定的目标。他不怕困难和危险。他必须去西田。他的意志是最坚定的。 孙悟空有一个强大的恶魔。猪善于试图赢得唐人的心灵, 他们可以赢得领 导。沙子是干燥的, 杆子是他的选择, 因此他们说, 在通往西方的路上, 它们 是必不可少的。然后我问学生, 让学生们思考我们的班级是否是一个团队,

联网的快速发展, 智慧党建将不断推陈出新, 不断革新高校党建工作新方 式, 高校党建工作才能如虎添翼, 实现既高效又智能的自我转变。

[参考文献]

[1]严佩升, 陈新芝, 严开强. 基于 “智慧党建” 的高校党建微信公众平 台研究[J]. 重庆电子工程职业学院学报,2018,27(06):23-26.

[2]谢俊波. “互联网+”时代党建知识服务平台的应用创新路径探究 [J].出版广角,2018,(20):51-53.

[3]苑兆忠.基于互联网+的高校 “智慧党建” 探索[J].山东千部函授大 学学报(理论学习),2018,(11):53-54. 